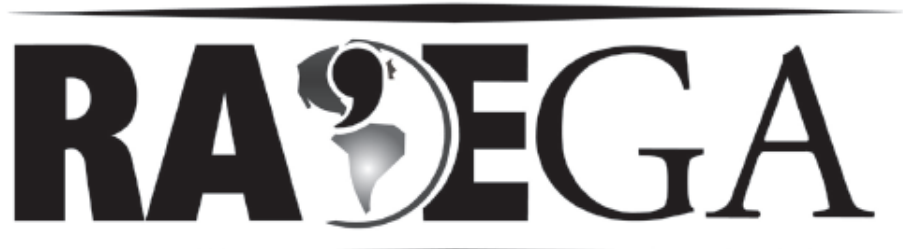

O ESPAÇO GEOGRÁFICO EM ANÁLISE

\title{
ENTRE CARISMA E PODER: O TERRITÓRIO E TERRITORIALIDADES DA ORDEM CAPUCHINHA EM CURITIBA A PARTIR DE SÃO FRANCISCO DE ASSIS
}

\section{BETWEEN CHARISMA AND POWER: THE TERRITORY AND TERRITORIALITIES OF CAPUCHIN ORDER IN CURITIBA FROM SAINT FRANCIS OF ASSISI}

\author{
Marco Aurélio Ghislandi ${ }^{1}$
}

\section{RESUMO}

Explorar o conceito de carisma a partir da pessoa de São Francisco de Assis, traduzindo-o como poder, e como estrutura estruturante, bem como compreendê-lo como elemento constitutivo dos territórios e territorialidades da Ordem Capuchinha em Curitiba-PR é o objeto central deste trabalho. Assim, buscando esta compreensão, serão aqui utilizados e trabalhados os conceitos de carisma e poder, território e territorialidade e habitus, os quais favorecerão a idéia de articulação entre estrutura estruturante (carisma de São Francisco de Assis), e as ditas estruturas estruturadas, da Igreja, da Ordem Capuchinha e da própria cidade de Curitiba, revelando as relações de poder que dali surge.

Palavras Chaves: Carisma; Poder; Território; Territorialidade.

\footnotetext{
${ }^{1}$ Mestre pelo Programa de Pós-Graduação em Geografia da Universidade Federal do Paraná - UFPR, Diretoria Executiva da Rede de Colégios - PMBCS, DERC, Brasil. feliz_mag@hotmail.com.
} 


\section{ABSTRACT}

To explore the concept of charisma from the person of Saint Francis of Assisi, translating it as power, and as a structural structure, in the same way that it is understood as a constitutive element of the territories and territorialities of the Capuchin Order in Curitiba-Pr, is the essence of this present study. Therefore, searching for perception, the concepts of charisma and power, along with the concepts of territory and territoriality and habitus, will be used and elaborated here, allowing the idea of articulation between the structural structure (Saint Francis of Assisi charisma) and the so said structured structures of the Church, of the Capuchin Order, and of the city of Curitiba, revealing the relations of power that emerge from there.

Key words: Charisma; Power; Territory; Territoriality.

\section{INTRODUÇÃO}

Este trabalho tem como objetivo principal apresentar análise das relações que constituem um território a partir do carisma de São Francisco de Assis. Personagem historicamente solidificado, e inspirador de vários estudos científicos em diferentes áreas do conhecimento, Francisco de Assis, a partir da proposta deste trabalho, passará a fazer parte também dos estudos da geografia, tendo como elemento articulador o seu carisma.

Para este propósito, foi necessário desenvolver uma concatenação e articulação entre os conceitos de carisma/poder, habitus e de território/territorialidade. Focado neste tripé conceitual, todo o trabalho visou compreender e demonstrar as relações possíveis que surgem a partir do território de origem franciscana, revelando em determinado ponto a presença de determinada territorialidade capuchinha, a partir do recorte espacial da cidade de Curitiba-PR.

Assim, a problemática foi concebida a partir das seguintes hipóteses:

a) Francisco de Assis, inspirador da formação de uma ordem religiosa, é portador de força carismática reconhecida como estrutura estruturante.

b) O carisma promove e mantém relações de poder, e pode ser traduzido como tal. 
c) O carisma de Francisco, incorporado pelos seus seguidores, determinaria uma institucionalização do carisma, gerando a promoção e manutenção de um determinado habitus.

d) A Ordem Franciscana dos Menores Capuchinhos (OFMCap.) como mantenedora e propagadora deste carisma, promove e constitui territórios e territorialidades desenvolvendo relações especificas com determinadas estruturas estruturadas em cada um deles.

Com base nestas hipóteses, no decorrer da reflexão e análises se querer demonstrar como o carisma ao se tornar uma estrutura estruturante, de caráter subjetivo, se relaciona com determinadas estruturas estruturadas (Igreja, Ordem Capuchinha e a cidade), gerando consequentemente relações sociais/poder com cada uma delas, determinando territórios e possíveis territorialidades.

\section{GEOGRAFIA DA RELIGIÃO E A DIMENSÃO INSTITUCIONAL DO SAGRADO}

Claramente, este trabalho tem como elemento principal a observação da religião pela ótica da geografia, a qual, é capaz de proporcionar uma melhor leitura do espaço vinculado ao campo religioso. Por este viés, tomou-se como base o âmbito da Geografia Cultural, mais especificamente o ramo chamado geografia da religião, pois, estruturalmente é o que tem condições de proporcionar trabalhos que compreendem a relação homem e religião, dentro do espaço.

Importa discorrer que no decorrer das últimas décadas, a geografia da religião tem apostado nos conceitos de sagrado e profano para realizar seus trabalhos. Por isto, conforme Rosendahl (2004) a religião na perspectiva da geografia cultural, teve e tem como uma dos seus focos centrais os conceitos de sagrado e profano, conceitos tornados fundamentais com Eliade (1962 [2001]) e considerados numa abordagem geográfica por Tuan (1979) e Rosendahl (2004).

Porém, atualmente, pode-se também afirmar que se inicia nova etapa dos estudos geográficos a partir da religião. O que passa a acontecer, não é 
mais uma geografia das religiões em si, ligada a uma descrição pura a partir das paisagens ou de simplesmente ligar a religião à cultura, mas sim, uma geografia da religião buscando seu aspecto mais essencial, o fenômeno religioso. A experiência do vivido e as representações sociais dos sujeitos passam a vigorar como meios de entender e explicar a religião no espaço. A religião deixa de ter seu aspecto meramente objetivo e ganha análises de seus aspectos subjetivos.

Com a contribuição da fenomenologia novos entendimentos surgem permitindo que as razões mais essenciais da experiência dos indivíduos sejam colocadas como objeto de estudo, fazendo com que o sagrado e o profano como modalidades essenciais para se estudar o homem e seus modos de ser no mundo, Eliade (2001) ganhem novas dimensões.

No intuito de melhor operacionalizar estes conceitos, importa observar o que nos diz Gil Filho (2002b) sobre categorias universais de análise do sagrado e suas dimensões possíveis.

1 - dimensão do homem em sua natureza individual, como primeira dimensão da prática espacial, corresponde à phisis social realizada no âmbito religioso...

2 - dimensão social ou da organização...

3 - terceira dimensão é a da instituição propriamente dita, a qual se realiza como ator da própria história por excelência e submete as pluralidades da dimensão anterior e expressa-se na fluidez vertical do poder hierárquico. $O$ espaço de representação constituído ao nível das relações sociais e de organização é diverso e plural em sua gênese. É subvertido pelas relações de poder e dos atores que a exercem. A instituição é o reino do controle do grupo, do indivíduo e do dizer. Constitui, assim, uma territorialidade na qual o agente principal é a própria instituição religiosa. (GIL FILHO, 2002b, p.263-264).

Mais recentemente, Gil Filho (2007) aprofunda esta reflexão do homem em face do fenômeno religioso, por meio da retomada dos escritos de Cassirer. Esta nova leitura propõe um novo modo de compreender o homem como sendo um ser simbólico. Por conseqüência, são as atividades humanas que remetem ao que se pode denominar "círculo de humanidades", incluindo assim o campo religioso. 
Desta forma, o espaço sagrado está regulado por determinadas espacialidades que se relacionam com a concretude das expressões religiosas, espacialidade do pensamento religioso e, a espacialidade das representações simbólicas.

Por está razão, o espaço sintético concebido pelo pensamento religioso guarda os contornos da idealidade narrativa próprias das tradições religiosas, que por sua natureza torna possível a verificação de suas condicionantes estruturais e de apropriação que relativo a ação social de apropriação, abarca em tese relações de poder, territorializando o espaço sagrado.

No caso específico, a partir da terceira dimensão apontada por Gil Filho (2002b), a qual se relaciona diretamente com a instituição e suas relações de poder, encontra-se certamente uma dimensão que melhor se enquadra neste estudo, pois, se efetiva em torno de uma instituição e de seus territórios específicos.

Deste modo, ao se optar pela dimensão institucional do sagrado na realização deste trabalho, colocando o carisma como conceito chave para a realização do mesmo, lança-se a vista às relações de poder que se desenvolvem a partir do carisma de São Francisco, por meio da Ordem do Frades Menores Capuchinhos.

Assim, a abordagem da dimensão institucional em suas relações com 0 carisma (elemento subjetivo) passa a ser o centro deste estudo; buscando desenvolver uma análise das relações de poder que deste encontro ocorrem se cristalizando nos locais em que está presente a Ordem Capuchinha na cidade de Curitiba-PR.

Desta forma, abordar o conceito de carisma se mostra necessário para o progresso do presente estudo e do desenvolvimento das problemáticas anteriormente levantadas: pois, é por meio deste que se poderá entender melhor a constituição dos locais de presença capuchinha, bem como classificálos como território ou territorialidades capuchinhas. 


\section{CARISMA E PODER: UMA RELAÇÃO SIMÉTRICA}

Dentro da história da humanidade, nunca foi tão pontual o surgimento de indivíduos que tivessem a capacidade de aglutinar em torno de si milhares de seguidores e modificar as estruturas de seu tempo. A estes indivíduos foi dado o pressuposto de serem eles mesmos reconhecidos como sujeitos carismáticos, ou melhor, sujeitos portadores de carisma.

Sem prejuízo ao trabalho, não se fará aqui uma discussão quanto a origem em si da natureza do carisma ou da força carismática; mas sim, reflexões que demonstrarão ser o carisma algo relacionado diretamente ao poder, ou de como o mesmo é elemento suporte para o exercício do poder, que neste caso, visto a partir do campo religioso como expressão da graça divina e da força sagrada, determina relação entre carisma e poder, que articulada ao conceito de território, proporcionará uma análise geográfica dos domínios territoriais da Ordem Capuchinha em Curitiba.

\section{O Carisma: um dom Sagrado para concretizar-se na terra}

Quando se analisa o conceito de carisma, percebe-se que o mesmo pode ser encontrado pela primeira vez nos textos de São Paulo, onde o termo ganha uma condição de "amor de Deus", ou melhor, carisma é a demonstração do amor de Deus e que pode ser dado a cada um quando necessário. (BÍBLIA, Coríntios I, 12: 4-11). Neste texto, fica clara a idéia de que estes "dons" ou "carisma" são de ordem diversa, mas que servem a um mesmo propósito.

Dentro deste enfoque, carisma passa a ser traduzido como uma graça concedida por Deus a uma determinada pessoa, mas em favor da Igreja. Tanto que, a Igreja Católica deixa bem clara esta questão quando coloca em seu discurso oficial este fato. Não é por menos que o Catecismo da Igreja Católica (1993, p.198) esclarece que "Sejam extraordinários e, sejam simples e humildes, os carismas são graças do Espírito Santo que, direta ou indiretamente, tem uma utilidade eclesial, ordenados que são à edificação da Igreja, ao bem dos homens e às necessidades do mundo".

É importante notar, que o discurso proposto estabelece uma ordem objetiva e funcional do Carisma, fica claro que o sujeito que os recebe, recebe 
em primeiro plano com o objetivo de edificar da Igreja. Aqui se demonstra 0 quanto a Igreja se posiciona como representante de Cristo entre os homens e que é por ela que a imagem de Cristo se revela. Identifica-se deste modo, uma intenção de trazer para o concreto 0 imaterial, os carismas tornam-se elementos de constituição, edificação da Igreja no mundo.

Todo este preparo discursivo acaba por garantir ao carisma um grau de relevância muito grande, dentro dos projetos da Igreja. Ele acaba por ser elemento importante na manutenção e expansão da Igreja.

Em caso mais específico, da Igreja Católica Apostólica Romana, surge a reflexão do que seja o significado de carisma na obra do teólogo e filósofo Leonardo Boff. Em alguma de suas obras, encontra-se a ideia de ser o carisma uma força estruturante, ou melhor, uma estrutura estruturante.

Com maior ênfase no capítulo XIII do livro "Igreja: Carisma e Poder", cujo título é: "Uma Estruturação Alternativa: O Carisma como Princípio de Organização", encontra-se no título uma função mais do que material para o carisma. É lógico que esta função está relacionada diretamente à Igreja:

O carisma constitui a estrutura estruturante da comunidade [...] o carisma não se inscreve mais no âmbito do extraordinário e inusitado, mas constitui o registro comum da estruturação comunitária. Destarte o carisma significa simplesmente à função concreta que cada qual desempenha dentro da comunidade a bem de todos. (BOFF, 1994, p. 255).

A ideia de Boff acaba por refletir quanto o carisma pode tornar-se concreto dentro do mundo, pois cada membro da comunidade que recebe 0 carisma, no mais amplo estrato social, deve transformá-lo em ação em favor da comunidade, no caso específico a Igreja.

Sendo que o carisma provém de uma linha vertical e se materializa em uma linha horizontal demonstra que a comunidade deve crescer a partir do carisma concedido por Deus. Tem-se, desta forma, definida uma relação entre o homem e o sagrado, da qual deve resultar a melhor edificação da comunidade. (BOFF, 1994, p. 263)

$\mathrm{Na}$ parte cinco do referido capítulo XIII, o autor escreve da seguinte forma: 
Se carisma significa o modo concreto como o Espírito e o Ressuscitado se fazem presentes no mundo, então devemos dizer que o carisma pertence à estrutura da Igreja. Sem ele, ela não se constitui como realidade religiosa e teológica [...] o carisma é mais fundamental que o elemento institucional. 0 carisma é a força pneumática que instaura as instituições e as mantém vivas. (BOFF, 1994, p.259).

Esta perspectiva sublinha mais ainda a função concreta do carisma, a certo modo uma maior posição superior do carisma como elemento. Porém, quando se lê a reflexão feita pelo autor, após dez anos do processo doutrinário promovido pelo Vaticano e que resultou na saída dele da estrutura hierárquica da Igreja, a relação carisma e poder fica ainda mais clara:

Não queremos uma Igreja de poder sem carisma, como não queremos uma Igreja de carisma sem poder. Queremos uma Igreja: carisma e poder. Os cristãos devem se habituar a essa dialética de inclusão do carisma com o poder e do poder com o carisma, porque somente assim conservam e expandem a força libertadora do Evangelho". (BOFF, 1994, p.346).

Portanto, na opinião de Boff a relação carisma e poder faz parte da existência do cristianismo, sendo o efeito desta relação à condição principal para que o cristianismo mantenha e expanda suas bases pelo mundo. Demonstrando que esta relação é então institucionalizada.

Nesta situação, se faz necessário registrar como último enfoque, ligado à experiência do carisma como advinda do sagrado, o que se entende por carisma institucional. Para tanto, segue abaixo o que se encontra na carta circular do superior geral do Instituto dos Irmãos Maristas:

Quando o carisma é usado para se referir a um Instituto religioso, assume sentido diferente daquele atribuído a uma pessoa. Há duas razões para essa distinção: o carisma de um Instituto tem longa permanência no tempo e é construído por muitas pessoas. Estes dois fatores - a permanência no tempo e a construção coletiva - transferem o carisma do domínio individual para o da Igreja como um todo". (SAMMON, 2006, p. 29).

Por este ponto de vista, o carisma que nasce a partir do individuo e que acaba por atingir outros, desenvolve um movimento de sua institucionalização. 
Fazendo isto, se torna algo estruturado; porém, como é responsável também pela manutenção e propagação da instituição, se torna estrutura estruturante. Deste modo, a permanência do carisma estará ligada à permanência da instituição que o captou e o utiliza para expandir e manter-se.

\section{CARISMA: uma força motriz}

Um dos primeiros a posicionar o carisma como elemento de análise dentro da sociologia foi Max Weber. Dentro dos ideais de racionalização do referido autor o carisma passa a não ser de caráter puramente transcendente, mas de caráter social. Não por menos, Weber destacará a ideia de que o carisma é um elemento que com o tempo deve ser institucionalizado, gerando estruturas de poder organizadas.

A forte ideia econômica presente nos escritos de Weber é preponderante e contém grande preocupação em estudar os sistemas de dominação na sociedade. Esta relação de domínio que se materializava na sociedade acabou sendo dividida pelo referido autor de três maneiras, determinada pelo próprio como legítimas e puras: a forma Tradicional, a forma Burocrática e a forma Carismática. Para os propósitos desta discussão a última forma é a mais relevante; para tanto é oportuno ler o que diz Weber sobre o que é o carisma:

Denominamos "carisma" uma qualidade pessoal considerada extracotidiana (na origem, magicamente condicionada, no caso tanto dos profetas quanto dos sábios, curandeiros ou jurídicos, chefes de caçadores e heróis de guerra) e em virtude da qual se atribuem a uma pessoa poderes ou qualidades sobrenaturais, sobre-humanos ou, pelo menos, extracotidianos específicos ou então se toma como enviada por Deus, como exemplar e, portanto, como "líder". O modo objetivamente "correto" como essa qualidade teria de ser avaliada, a partir de algum ponto de vista ético, estético ou outro qualquer, não tem importância alguma para o nosso conceito: o que importa é como de fato ela é avaliada pelos carismaticamente dominados - os "adeptos". (WEBER, 2000, p.158-159).

Em primeiro plano se percebe que o carisma weberiano se liga a uma questão mais pessoal, de caráter mais interno do que externo. $O$ homem que 
compreende determinadas qualidades acaba por dominar ou encantar os outros homens, fazendo deles seguidores.

A idéia de que aquele que detém um carisma deve demonstrá-lo, para pôr legitimidade em sua autoridade, torna-se uma responsabilidade própria do homem carismático.

O carisma pode ser, e decerto regularmente é qualitativamente particularizado. Trata-se mais de uma questão interna do que externa, e resulta na barreira qualitativa da missão de poder do portador do carisma... se quer ser profeta, deve realizar milagres; se quer ser senhor da guerra, deve realiza feitos heróicos. Acima de tudo, porém, sua missão divina deve ser "provada", fazendo que todos os que se entregam fielmente a ele se saiam bem. Se isso não acontecer, ele evidentemente não será o mestre enviado pelos deuses. (WEBER apud RAMOS, 2006, p.56).

Para Weber, o carisma tenderia a desaparecer ou, em outro sentido, o carisma para sobreviver teria de ser "rotinizado", teria de ser modificado, acabando por ser o mesmo racionalizado. Esta racionalização do carisma caminharia ao encontro da forma tradicional, pois a autoridade do senhor carismático passaria a seus sucessores.

Vê-se aqui o surgimento do apostolado ou séquito carismaticamente qualificado, com o reconhecimento de uma comunidade que mantém, via "eleição" o sucessor do carisma.

Percebe-se por fim que o trabalho de Weber identificava o carisma como qualidade pessoal de um determinado sujeito e que se concretizava na relação deste sujeito com os outros indivíduos que o seguiam. Porém o maior destaque está na análise da rotinização deste carisma.

Por meio desta rotinização fica valida a idéia de o carisma fundamentar determinado habitus, que será internalizado por seguidores e exteriorizado em algum momento.

Outro importante autor a discutir a temática do carisma foi Pierre Bourdieu. Bourdieu (2002 e 2003) aponta destacadamente para uma relação entre comunidade e o líder carismático. Este entendimento está centralizado na idéia de que o líder carismático não se mantém pela sua força simbólica, mas sim no poder que exercem os grupos sociais que ele representa. 
Max Weber, inclusive em seus textos mais rigorosos, propõe apenas uma teoria psicossociológica do carisma como relação vivida do público com o personagem carismático: "Por 'carisma', deve -se entender uma qualidade considerada como extraordinária [...] que é atribuída a uma pessoa. Esta é considerada como dotada de força e de propriedades sobrenaturais ou sobre-humanas, ou, pelo menos excepcionais". A legitimidade carismática tem então como fundamento apenas um ato de reconhecimento". Para romper com esta definição, é preciso considerar a relação entre o profeta e os discípulos leigos como um caso particular da relação que se estabelece segundo Durkheim, entre um grupo e seus símbolos religiosos: o emblema não é apenas um simples signo que exprime "o sentimento que a sociedade tem de si mesma"; ele constitui este sentimento. (BOURDIEU, 2002. p. 92).

Através do que diz Bourdieu, pode-se confirmar sua idéia de como se deve entender o carisma ou o líder carismático. Neste ponto é que surgem com força, na análise de Bourdieu, o entrelaçamento dos conceitos de Campo e Habitus, que o autor defende em suas obras.

Em breves palavras pode-se dizer que habitus seria o seguinte:

O Habitus pode ser entendido como um sistema de esquemas de pensamento interiorizados e socialmente constituídos, que é capaz de originar todos os pensamentos, percepções e as ações características de uma cultura [...]. Sendo o habitus um princípio gerador das práticas de um indivíduo (sendo o habitus original o habitus de classe), deve-se, portanto, entender as práticas sociais conforme o campo de que o individuo participa e o habitus que possui. Ou seja, o habitus indica a ação dos agentes na inter-relação entre diversos campos e em um campo específico. (KULAITIS, 2004, p. 12).

É salutar perceber que na definição do que seria o habitus, surge conjuntamente o conceito de campo. Pontue-se que os dois conceitos podem proporcionar melhor definição e operacionalização do que seria o carisma para Bourdieu. Deste modo, importa lembrar que o campo de modo amplo seria um espaço simbólico, onde se estabeleceria uma série de classificações oriunda da luta entre os agentes envolvidos, os quais validam determinadas representações. Em caso específico, dentro da presente reflexão é o campo religioso.

É por meio do conceito de habitus, nos termos de Bourdieu, que se efetua uma articulação entre carisma/poder e território; visto que, todo o 
território, a ser analisado mais a frente, dependerá da visão (habitus) dos agentes (neste caso dos frades capuchinhos) diretamente a ele relacionados, presentes na instituição religiosa.

\section{HABITUS: um princípio de ligação}

Pode-se dizer que habitus, segundo Bourdieu (2002, p.191), é visto como "sistema das disposições socialmente constituídas que, enquanto estruturas estruturadas e estruturantes, constituem o princípio gerador e unificador do conjunto das práticas e das ideologias características de um grupo de agentes". Trata-se de um meio sistemático de pensamentos interiorizados e constituídos que, de certo modo, orientam as escolhas dos indivíduos a ele relacionados.

No caso da Ordem dos Capuchinhos, instituição organizada com suas próprias regras e hierarquias fundamentadas no carisma de São Francisco, se percebe que a ideia de habitus pode compreender muito bem esta estrutura.

Este habitus, ainda na reflexão de Bourdieu (2002, p. 201), é um:

Sistema de disposições inconscientes que constitui o produto da interiorização das estruturas objetivas e que, enquanto lugar geométrico dos determinismos objetivos e de uma determinação, do futuro objetivo e das esperanças subjetivas, tende a produzir práticas e, por esta via, carreiras objetivamente ajustadas às estruturas objetivas. (BOURDIEU, 2002, p.201/202).

Pode-se pensar que o habitus seja responsável por uma produção de praticas e representações que permitem uma classificação, a qual está inteiramente relacionada às estruturas internalizadas pelos agentes. Neste aspecto, ao interiorizar o carisma franciscano proposto por uma instituição orgânica, no caso a Ordem dos Frades Capuchinhos, cada sujeito passa a orientar suas escolhas a partir deste carisma. Assim, toda a forma de exteriorização, seja das praticas, seja das representações desses agentes, terá como fundamento particular o carisma por eles mesmo incorporado. Deste modo, a cada escolha realizada e relacionada a um determinado espaço, sempre suporá uma classificação, uma representação ideal. 
Particularmente em relação a uma Ordem religiosa, pode-se então dizer que cada espaço, ligado a mesma, sempre terá como fundamento central a presença do seu carisma; porém as relações de poder em cada espaço poderão ser distintas. Mas o que importa salientar é que quando se percebe a incorporação do carisma, neste caso o franciscano, por determinado agente, o qual ocorre devido à existência de uma estrutura institucional orgânica, o objetivo de tal incorporação é fazer com que o carisma passe a orientar suas escolhas e suas representações.

Existem relações entre a vida e o cotidiano que se realizam em determinadas condições e na posição do sujeito na estrutura religiosa. A partir da identificação positiva destas relações, configura-se uma classificação objetiva das práticas. A caracterização das práticas, por sua vez, forma o habitus religioso estruturado e dialeticamente estruturando a estrutura. Trata-se de um conhecimento adquirido a partir de uma prática, mas que também indica um capital simbólico incorporado pelo sujeito. (GIL FILHO, 2002a, p. 40).

Desta forma, pode-se pensar que, para cada espaço determinado onde este sujeito age, sempre existirá a influência do carisma; porém sua representação poderá ser variada nas relações sociais que ali se desenvolvem.

\section{TERRITÓRIO-TERRITORIALIDADE: O PALCO DAS MARCAS DO PODER}

Em Raffestin (1993, p.143-144) temos a seguinte ideia: "O território [...] é um espaço onde se projetou um trabalho, seja energia e informação, e que, por consequência, revela relações marcadas pelo poder. O espaço é a 'prisão original', o território é a prisão que os homens constroem para si”.

Esta definição pontual, onde aponta o território como sendo o espaço das relações de poder, é certamente importante. Não é por menos que em sua obra: Por uma Geografia do Poder, é natural encontrarmos este pensamento: "o poder visa ao controle e à dominação sobre os homens e sobre as coisas [...]. O território não é menos indispensável, uma vez que é a cena do poder e o lugar de todas as relações". (RAFFESTIN, 1993, p.58)

Lê-se; deste modo, que o território passa a ser o cenário de uma constante manifestação de produção do espaço, tendo como facetas as 
questões de apropriação, controle, domínio, usos de energia e informação. A ênfase dada às relações de poder acaba por fazer do território um trunfo particular do poder (RAFFESTIN, 1993, p.59). Assim, a formação de um território passa a ser o resultado de uma ação orientada por um ator sintagmático (RAFFESTIN, 1993, p.143).

Articulando as ideias de Raffestin (1993), pode-se colocar a Igreja, bem como uma ordem religiosa, como um ator sintagmático; porquanto, como sintagma no grego remete à idéia de batalhão, algo organizado, hierarquizado, fica fácil relacioná-lo à Igreja. Portanto, capaz de apropriar-se de um espaço e fazê-lo território.

O ator sintagmático manifesta com precisão a idéia de processo e de articulações sucessivas no interior do processo. Assim, todas as organizações, da família, ao Estado, passando pelos partidos, pelas igrejas e as empresas são atores sintagmáticos [...]. Isso significa que o ator sintagmático articula momentos diferentes da realização do seu programa pela integração de capacidades múltiplas e vaiadas. Esses atores sintagmáticos são, portanto, constituídos por atores-indivíduos que se integram ou são integrados num processo programado. (RAFFESTIN, 1993, p.40).

Ao analisar a explicação de Raffestin sobre o ator sintagmático, pensando-a na Ordem dos Capuchinhos, pode-se entender que a ordem em si é um ator sintagmático, a partir de sua organização institucional, e que ela é resultado da existência de indivíduos que nas suas intenções estão inseridos. Deste modo, os frades capuchinhos seriam estes indivíduos que quando ligados por um carisma, neste caso no carisma de São Francisco, acabam por continuarem sendo indivíduos múltiplos, com atitudes múltiplas agindo em espaços variados. Porém, como possuem determinado habitus, proposto pela instituição em si, suas escolhas acabam no final tendo relação ao que está no processo programado pelo ator sintagmático maior.

Nesse sentido, é importante pensar as relações que existem entre a Ordem Capuchinha e a Igreja Católica Romana, a Ordem Capuchinha e o Estado, bem como as relações internas da própria ordem, como formas de manter e expandir sua própria existência, originando territórios. De qualquer maneira como se está trabalhando com determinadas estruturas institucionais, 
entendidas neste trabalho como estruturas estruturadas, que mantêm relações diretas com o carisma de São Francisco (estrutura estruturante), não resta dúvida de que destas relações se projetarão também em territorialidades.

A territorialidade pode ser compreendida em primeiro plano pelo que diz Raffestin (1993, p.161):

Territorialidade resume, de algum modo, a maneira pela qual as sociedades satisfazem, num determinado momento, para um local, uma carga demográfica e um conjunto de instrumentos também determinados, suas necessidades em energias e em informação.

Percebe-se que a territorialidade é resultado de uma contínua relação de poder entre agentes específicos, que se relacionam a um território. A territorialidade é multidimensional e relacionada ao vivido, está ligada aos aspectos do real, do sensorial e das representações.

Toda esta argumentação sobre a territorialidade, como atinente a um sistema territorial, permite pensar que, quando estruturas distintas se articulam em um determinado território, tem-se a origem de determinadas territorialidades. Percebe-se também que estas territorialidades, não dissolvem o território em si; o que há, na verdade, é um ajustamento, sejam eles pelo caráter de estabelecer ou não simetrias. No caso específico do carisma, ao estabelecer uma relação com uma estrutura estruturada, o mesmo trará à tona determinadas relações de poder que serão cristalizadas em um território e também produzir e manter territorialidades a partir de sua força representativa.

Dentro do foco religioso a territorialidade é plena de atributos:

Cabe ressaltar que: a apreensão do território como categoria privilegiada de análise da religião encerra possibilidades de uma conexão pertinente entre as estruturas dos sistemas simbólicos e as estruturas do sistema territorial, o território é o objeto (restrição do espaço), o sistema territorial a lógica desse conjunto estrutural e a territorialidade $o$ atributo de determinado fato social onde o poder é imanente. Define-se territorialidade do sagrado como sendo a percepção das limitações imperativas do controle e gestão de determinados espaços sagrados por parte de uma instituição religiosa. (GIL FILHO, 2003, p.96). 
Apontada à relação entre território e territorialidade, pode-se pensar com mais propriedade nas relações entre carisma como estrutura estruturante e a Igreja e a Ordem Capuchinha como estruturas estruturadas.

Assim, ao avançar nas reflexões, se faz necessário efetivar um resgate da pessoa de Francisco de Assis e de seu carisma, em que apareçam as relações entre carisma/poder, Igreja e a Ordem Franciscana; esta vista como instituição portadora, mantenedora e propagadora do carisma de Francisco de Assis. Tal tentativa visa demonstrar como estas relações podem ser cristalizadas no território e podem seguramente desenvolver determinadas territorialidades.

\section{FRANCISCO E O SEU PODER CARISMÁTICO}

Nascido na região da Úmbria, em uma cultura medieval, e em meio ao período de uma mudança social e econômica, surge Francisco Bernardone. Filho de próspero comerciante e educado na vida cavalheiresca da época, durante a juventude tentou consagrar-se cavaleiro e fez-se prisioneiro em tempos de guerra. Apaixonado pela vida desregrada e aventureira, nunca teve apreço pelos pobres, muito menos pelos doentes. Porém, em determinado momento de sua vida, algo mudou. A vida proporcionou uma mudança interior em Francisco e assim deu-se o início da sua grande transformação: houve o despertar, o surgimento de novo homem, um novo Francisco.

É deste novo Francisco que surge um novo modo de seguir os ideais de Cristo durante o século XIII, e que acaba promovendo o aparecimento de uma nova ordem religiosa que, mais adiante, vai desdobrar-se em três troncos, (incluindo uma feminina) dentro da Igreja Católica Romana, a qual até então tinha como base de sua manutenção e expansão basicamente a ideia da vida monástica.

Deixando de lado a prática estritamente regulada ao claustro e avançando em direção ao povo, que se encontra em outros locais, seja a cidade, ou campo, seja rico ou pobre, seja qualquer criatura, todos devem receber a mensagem de Cristo e serem considerados criaturas de Deus e assim amados profundamente. 
A figura de Francisco que, no início de sua vida de povertá, havia sido desaprovada publicamente pelo pai, com o tempo foi atraindo uma multidão de seguidores; o modo de vida "segundo o evangelho" de Francisco passou a ser o modo de vida de muitos. Francisco não cogitava criar uma fraternidade sem permissão da Igreja, tudo o que o movimento originado a partir da vida de Francisco viesse a conseguir, conseguiria em nome da Igreja. Esta relação de subordinação, que sempre foi ratificada pelo próprio Francisco, acabou por trazer grande benefício às estruturas da Igreja. A força atrativa de Francisco motivava, e ainda hoje motiva, muitos sujeitos a segui-lo e de certo modo, subordinar-se ao Papa.

A força da figura carismática de Francisco é tamanha que, no dizer de Merlo (2005, p.17) "[...] o arquétipo São Francisco não age apenas entre seus filhos; exerce uma fascinante atração difusa, como santo e como Francisco de Assis". Esta afirmação de um dos maiores franciscanólogos da atualidade vem confirmar a força do carisma franciscano e sua capacidade de criar mudanças sociais e religiosas entre os homens.

Pontuada a potência do carisma de Francisco em inspirar atividades humanas, pode-se perceber sua presença nas relações e efeitos do poder e, a partir disto, percebê-lo cristalizado claramente no espaço.

\section{Francisco e a Igreja: Um Discurso de Apropriação Cristalizado no Território}

A ligação de Francisco à Igreja, só vem a reforçar a idéia de que tudo o que o carisma franciscano viesse a conquistar, o estaria em nome da lgreja. Tal incorporação e subordinação do carisma de Francisco à lgreja pode ser visualizado no espaço. Um exemplo da cristalização do discurso incorporador de direito da Igreja é percebido quando se procura na cidade de Assis o local onde a Ordem Franciscana teve início, ou melhor, onde Francisco vivenciou a maior parte das suas experiências religiosas. Neste local, existe uma capela de proporções humildes $(4 \times 7 \mathrm{~m})$ a qual Francisco reconstruiu para viver fora da cidade, conhecida como "Porciúncula", e que até os dias atuais lá continua. Este local é considerado um local sagrado; porém todo o que lá chega se 
surpreende ao encontrar cobrindo a capelinha uma enorme catedral conhecida pelo nome de Santa Maria dos Anjos. Este fato demonstra uma real sobreposição de elementos, caracterizando verdadeira relação de poder que se manifesta no espaço. Assim, a capelinha que possui suas proporções relacionadas à atividade pessoal de Francisco, com suas experiências religiosas pessoais, assume uma nova proporção: existe uma re-dimensão na abrangência do local. A grandeza da catedral incorpora a grandeza simbólica da capelinha à instituição Igreja e demarca o local da experiência sagrada e pessoal de Francisco, com seu poder: demonstrando claramente a legitimidade que ela possui em incorporar para si tudo que se relaciona a Francisco.

\section{São Francisco e a Ordem Franciscana: O Vigor de um Carisma}

Tendo passado oitocentos anos do surgimento da primeira fraternitas, não restam dúvidas de que a Ordem Franciscana é uma das ordens religiosas mais importantes da Igreja Católica. O vigor da Ordem fundada por Francisco, em torno de seus primeiros companheiros, acabou por gerar vasta fraternidade de irmãos, não importando se homens ou mulheres, pois como legado ele inspirou e instituiu o que atualmente se reconhece como a Ordem dos Frades Menores, Ordem de Santa Clara e a Ordem Franciscana Secular.

Sendo a Ordem Franciscana reconhecida como instituição, e naturalmente portadora, mantenedora e herdeira legítima do carisma franciscano, pode-se dizer que a partir da Ordem constituída surge o carisma institucionalizado. Por este ângulo, o carisma como ressalta Boff (1994, p. 255), "passa a ser considerado uma 'estrutura estruturante"'. Sendo assim, o carisma preso à experiência pessoal de seu agente passa a organizar-se a partir da comunidade que dele compartilha.

Com este organizar, aparecem também as estruturas de manutenção deste carisma, que, de certo modo, serão materializadas em estruturas fisicamente constituídas. Ao surgirem seguidores dispostos a viver segundo 0 jeito de Francisco, será também necessário organizá-los em determinados postos. Nasce então a necessidade de formar locais específicos para aqueles que desejam adentrar a ordem. 
Estes locais, específicos devem traduzir, em grau máximo, determinada identidade, pois isso trará uma unidade em torno de seus membros. Em se tratando da Ordem Franciscana, seriam inúmeros os locais que expressariam esta identidade e que manteriam o carisma com vigor, capaz de atrair sempre novos adeptos.

Dentre estes, podem ser lembrados os seminários, as igrejas dedicadas a São Francisco, as igrejas comandadas por franciscanos, os educandários franciscanos, casas de formação e tantos outros, que estariam constituindo uma territorialidade especifica da Ordem.

De outra maneira e por meio de outra relação, o que se percebe também, é que de algum modo, todos estes locais acabam por exteriorizar a presença do carisma de Francisco de Assis. Este ato, que demonstra possuir relação com o que é religioso, abre espaço para promover o habitus franciscano.

Ao passo que o carisma de Francisco funciona como estrutura de atração de novos sujeitos à Ordem, em sentido conjunto, cria estruturas que devem manter e promover a reprodução deste ciclo. Portanto, sem o carisma as estruturas criadas perdem sentido; mas, sem as estruturas, o carisma pode correr o risco de esvaziar-se. Sendo assim, tais estruturas compõem uma territorialidade própria, portanto uma territorialidade franciscana.

\section{TERRITÓRIO, HABITUS, CARISMA E PODER: UMA ARTICULAÇÃO POSSÍVEL}

Buscando efetivar a relação entre carisma e poder, habitus e sua cristalização no território, de modo articulado, pode-se, de início, apontar que o território é aquilo que congrega significados e símbolos, sendo o espaço delimitado e pleno de relações de poder.

No caso do carisma que foi bem trabalhado por Max Weber, tratando-o como sendo uma forma pura de dominação legítima, o referido conceito pode ser traduzido como poder.

A autoridade carismática baseia-se na "crença" no profeta ou no "reconhecimento" que encontram pessoalmente o herói guerreiro, o herói da rua e o demagogo, e com eles cai [...]. 
Sem dúvida, a autoridade carismática é uma das grandes forças da história, porém em sua forma totalmente pura tem caráter eminentemente autoritário e dominador. (WEBER, 1979, p.136).

Esta tradução do que seja a autoridade carismática e por conseqüência a forma de exercitar uma relação de poder pensada por Weber, dá condições de ler o carisma como poder.

Em caso particular, sobre a existência de uma determinada autoridade carismática relacionada à pessoa de Francisco de Assis, pode-se ler o que o próprio Weber (1999, p.325) diz em uma de suas mais importantes obras: "Não é raro, sem dúvida, que o carisma condena conscientemente a posse de dinheiro e as receitas correspondentes, puramente como tais, como São Francisco e muitas figuras semelhantes". A força carismática encontrada em Francisco não é baseada na política ou economia, ela provém de outro campo, o campo religioso.

Ao dedicar atenção à religião como forma de exercício de poder, Raffestin (1993, p.119) afirma que "o fenômeno religioso é caracterizado por relações de poder", o que acaba por permitir relacionar a questão do carisma de Francisco ao território.

Quanto à relação entre o poder e o território, Raffestin nos esclarece:

O poder visa o controle e a dominação sobre os homens e sobre as coisas [...]. O território não é menos indispensável, uma vez que é a cena do poder e o lugar de todas as relações [...]. O território é um trunfo particular, recurso e entreve, continente e conteúdo, tudo ao mesmo tempo. (1993, p.58).

Percebe-se que território e poder são simetricamente relacionados; portanto o carisma, como forma de poder também o é.

A concepção de uma dimensão institucional do sagrado permite que se construa uma relação entre o carisma pessoal de Francisco e a sua transposição à Ordem Franciscana; pois é por este ato que os seguidores de Francisco acabam por originar e reproduzir o habitus franciscano e, na seqüência, institucionalizá-lo dando margem assim a toda a análise dos espaços por esta ordem mantidos. 
Assim, mesmo que o carisma seja subjetivo em sua essência, seus efeitos são concretos. Pode-se dizer que não há desgaste no ato de se relacionar paralelamente com diferentes estruturas, mas, há demonstração de vigor e capacidade de flexibilização.

Toda esta fluidez potente, ao ser introduzida nas estruturas estruturadas, acaba por permanecer nelas e cristalizar-se de algum modo no espaço. Seja direta ou indiretamente, produz territórios ou territorialidades.

Pensando desta forma o carisma se institucionaliza na Ordem Capuchinha, fazendo com que ao mesmo tempo a instituição pelo carisma e o carisma se mantenha por meio dela. Tal relação se caracteriza como uma relação de coexistência, apesar de se perceber que de modo geral o carisma franciscano transcende a própria ordem.

Desta relação surge 0 aspecto formativo do agente que está relacionado diretamente à Ordem Capuchinha, o qual acaba incorporando o carisma, traduzindo-o em habitus. Para tanto este carisma, para ser incorporado, necessita de locais específicos para ser apreendido; gerando, portanto, territórios próprios do carisma dentro da ordem, ou melhor, territóriosterritorialidades de promoção e manutenção do habitus, na sua essência.

\section{FRANCISCANISMO: A FORÇA E MULTIPLICIDADE DE UM CARISMA E SUAS TERRITORIALIDADES}

Constatado desde suas origens como uma força propulsora, o carisma de São Francisco incorporado a partir de seu surgimento de maneira diversa desde o surgimento da $1^{\text {a }}$ Ordem Franciscana, não se restringiu unicamente àquele grupo especificadamente. A Ordem Primeira de São Francisco de Assis atualmente dividida em três ramos: Frades Menores, Conventuais e Capuchinhos, reflete prontamente este vigor.

Ao se observar toda esta capacidade de gênese, o carisma de São Francisco acaba por gerar não uma única Ordem, mas o que pode ser considerado um movimento franciscano, ou melhor, o franciscanismo, identificado como família franciscana. 


\section{Os Frades Menores Capuchinhos: A Nova Franciscanidade}

Elemento desta análise a Ordem dos Frades Menores Capuchinhos, surge nas primeiras décadas do século XVI. Anteriormente a $1^{\text {a }}$ Ordem Franciscana, até então composta pelos Frades Menores Conventuais e Observantes, vinha passando por momentos de disputas internas pela liderança institucional da Ordem. Em meio a um clima de conflitos e divisões, assiste-se ao crescimento de um desejo por parte de alguns indivíduos de viver uma "mais estreita observância" dos ideais franciscanos. Dedicar-se a praticar a rigorosa pobreza e a contemplação era a busca de muitos.

Este ideal de isolamento e de uma vida itinerante fez surgir a experiência dos "Frades menores de vida eremítica". Esta experiência recebeu um número expressivo de novos membros logo em seu início; dez anos depois, passou a contar com o nome de "Frades Menores Capuchinhos", a qual vem difundindo sua presença pelos países, expandindo cada vez mais o carisma de São Francisco e os domínios da Ordem Franciscana.

\section{As estruturas da Ordem dos Frades Menores Capuchinhos: Território e territorialidade}

Importante registrar que a ordem possui um governo central e está dividida em Conferências, Províncias, Vice-províncias, Custódias, Casas e Fraternidades locais, podendo ser acrescentadas as delegações e as Casas de presença.

Conforme as orientações da Ordem Capuchinha, a partir de publicação interna de orientações "Conhecendo os Freis Capuchinhos" (2000, p.54-55), pode-se definir cada divisão da seguinte forma:

a) Conferência é formada pelos ministros provinciais, vice-provinciais e pelos superiores regulares de qualquer região ou território, constituídas pelo ministro geral com o consentimento do definitório.

b) Província é constituída de um grupo de freis e de fraternidades locais; este tem um território próprio, com o seu ministro provincial.

c) Vice-Província é uma parte de Ordem, constituída de um determinado território, ligada diretamente ao ministro geral (ou vice- 
provincial geral), ou confiada a qualquer província (vice-província provincial); esta é confiada a um ministro vice-provincial na qualidade de vigário do ministro geral ou provincial respectivamente.

d) Custódia (ou Missão) é um grupo de freis que, pertencendo a uma província, atendem à obra missionária de um determinado território e são governados por um superior regular como vigário do ministro geral.

e) Fraternidade local: é um grupo de, ao menos, três freis professos, que vivem numa casa legitimamente erigida, tendo um superior local ou guardião.

f) Delegação: denominação não inserida nas Constituições, mas usada na prática para designar um grupo de freis e de fraternidades locais que iniciam a Ordem num determinado território e dependem diretamente do ministro geral (delegações gerais) ou de qualquer província (delegações provinciais).

g) Casas de presença, residência ou presença: trata-se de uma realidade análoga à precedente, mas mais reduzida, que não preenche as condições para formar uma delegação e que permanece incorporada a uma província.

Fica clara em todas estas divisões a presença de um território determinado, e que sempre estará subordinado a uma das escalas de poder dentro da Ordem.

A partir desta constatação, pode-se propor que a Ordem Capuchinha estabelece estruturas específicas dentro dos seus domínios, quanto a seu território.

Para entender estas estruturas, vale observar o que Gil Filho (2006) assevera sobre a territorialidade católica e que pode servir também para 0 entendimento da Ordem Capuchinha:

Dois grupos de estruturas da territorialidade católica são discerníveis: 1. As estruturas da territorialidade de base caracterizadas pela interação social entre a população e a Igreja através do clero. 2. As estruturas da territorialidade católica derivadas, representadas por estruturas de hierarquia 
e/ou escala atinentes à macroestrutura administrativa da Igreja. (GIL FILHO, 2006).

Esta ideia de que a territorialidade, num primeiro ponto, está centrada em base relacional entre o povo e a Igreja pode ser bem percebida na dimensão da paróquia, em primeiro lugar, e depois nas escolas, hospitais e instituições beneficentes e nos locais sagrados de peregrinação.

Num segundo ponto, a territorialidade apresenta-se a partir de uma articulação hierárquica e política: as dioceses e arquidioceses, Conferência Nacional dos Bispos, Conselho Episcopal e Santa Sé.

Toda esta organização pode, de modo particular, ser retomada e relacionada também à Ordem Capuchinha.

Para tanto a divisão da Ordem Capuchinha, acima exposta, pode enquadrar-se perfeitamente na estruturação derivada, representada pela hierarquia: Governo Geral, Conferência, Província, Vice-Província, Custódia, Fraternidades, Delegações e casas de presença.

Por outro lado, as demais estruturas estariam relacionadas às estruturas de base da Ordem: paróquias, conventos, casa de retiros, centro sociais, leprosário, hospitais, entre outros.

\section{Os espaços Capuchinhos em Curitiba}

Especificadamente como dito anteriormente 0 presente trabalho objetiva analisar algumas das relações de poder que acontecem nos espaços de presença capuchinha da cidade de Curitiba - Mapa "Presença Capuchinha em Curitiba". Pois é em meio a estes locais que se estabelecem determinadas relações de poder, as quais se cristalizam no território. 
A ação capuchinha em Curitiba compreende os seguintes espaços: o Convento Nossa Senhora das Mercês, a Igreja Nossa Senhora das Mercês, a casa Provincial, a casa de Oração Nossa Senhora dos Anjos, a Igreja Nossa Senhora da Luz dos Pinhais e a Capela São Leopoldo Mandic.

Cada um desses locais possui uma determinada função e desenvolve suas relações de poder. Por exemplo:

A missão da fraternidade São Lourenço de Brindes da Sede Provincial,

Presença Capuchinha em Curitiba

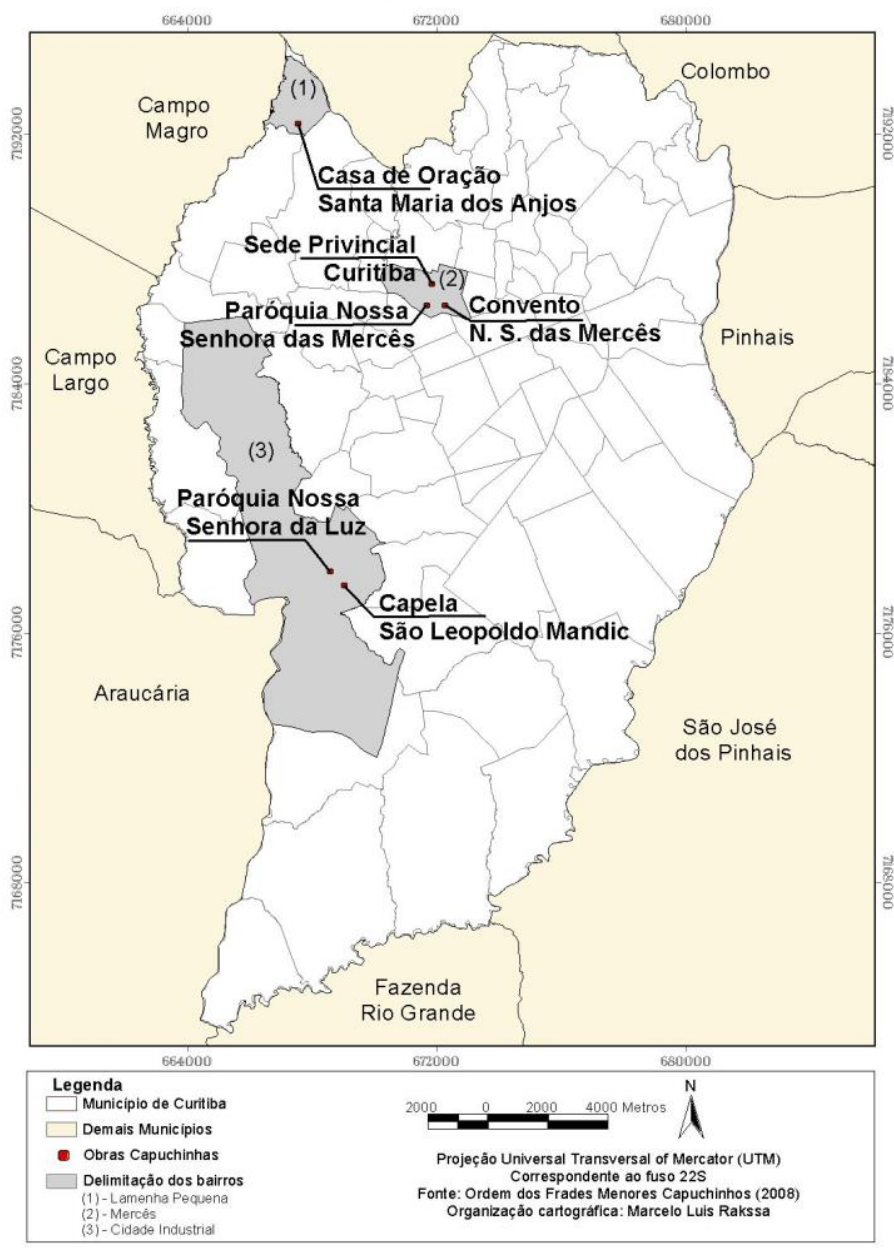
situada em Curitiba-PR é "testemunhar evangelicamente Jesus Cristo, lutando por uma vivência dos valores franciscanos capuchinhos e que organize a administração dos serviços provinciais, acolha fraternalmente aos frades visitantes e empenhe em favorecer uma ação participativa, buscando inspirar confiança e paixão pela missão provincial".

O objetivo do Convento é "ser testemunha de vida minorítica; Frades penitentes e orantes procuram viver à fraternidade, como anúncio profético do Reino de Deus, em comunhão eclesial e provincial, e com disponibilidade para atender o povo, serviço fraterno de acolhimento aos hóspedes e no atendimento aos Frades idosos e dos que vêm para consultas e exames médicos. Na fraternidade residem os Frades Missionários, os Frades que atendem à Paróquia Nossa Senhora das Mercês e os Frades que administram as bênçãos". 
Quanto à Paróquia Nossa Senhora das Mercês, o ideal é servir ao povo com 0 atendimento espiritual, confissões, bênçãos, acolhimento psicológico e realizar o ato litúrgico da celebração da eucaristia.

Já a Casa de Oração Nossa Senhora do Anjos, tem como objetivo principal servir de local de retiro espiritual para os frades.

Por fim, a Paróquia Nossa Senhora da Luz dos Pinhais e a Capela São Leopoldo Mandic atendem ao povo nas suas necessidades espirituais; porém, nestes espaços ocorre também o desenvolvimento de um trabalho social muito intenso - desde creche até cursos de panificação e corte costura, por exemplo - que busca o desenvolvimento e promoção humana.

\section{DISCURSO E VIVÊNCIA: A REPRESENTAÇÃO DE UM IDEAL}

Efetivado o processo de clarificação dos conceitos e realidades situacionais deste trabalho, esta parte da análise se dará pela ótica do entendimento do efeito do Carisma; ou seja, o referido conceito será aqui compreendido como sistema que gera esquemas de percepção e de produção de determinadas práticas, e que estão diretamente relacionadas aos agentes e instituições. No centro desta sequência pretende-se evidenciar algumas representações sobre "o ser capuchinho", expressas por alguns dos frades capuchinhos $^{2}$ de Curitiba. Esta identificação nos faz perceber mais nitidamente a presença do carisma de São Francisco nos referidos agentes e instituições. Ainda para completar o raciocínio, visando uma reflexão mais pontual, abaixo seguirá resultado de análise de alguns espaços capuchinhos para evidenciar algumas das suas territorialidades.

\section{CAPUCHINHOS: OS FILHOS DE FRANCISCO}

Representado discursivamente pelos frades como inspirador dos capuchinhos e seus seguidores, São Francisco intensifica nestes o objetivo de seguir o Evangelho e servir a Igreja, assim como fizera o próprio Santo. Esta

\footnotetext{
2 Entrevistas concedidas por ocasião do nosso projeto de pesquisa, que resultou na Dissertação de Mestrado, de mesmo título deste artigo, defendida no Programa de PósGraduação em Geografia da UFPR em 2008.
} 
postura, que é forjada em cada um dos fiéis, acaba demonstrando o quanto a institucionalização de um ideal, permite que não ocorram variações muito extremas entre membros de um determinado grupo, neste caso a Ordem dos Capuchinhos - visto que a representação carismática de São Francisco mantém certo padrão entre os seguidores.

O discurso institucional, que serve como elemento de formação dos frades, e que é interiorizado, se manifesta nas escolhas que cada membro da Ordem Capuchinha faz. Estas escolhas se refletem diretamente nos espaços em que os capuchinhos se fazem presentes. Portanto nessa dinâmica vê-se a presença daquilo que reconhecemos como habitus.

Em um exemplo específico, o discurso institucional capuchinho aponta a Igreja Católica Romana como acolhedora da proposta de Jesus, e sendo um capuchinho um seguidor de Jesus, nas pegadas de São Francisco, não resta dúvida - conforme o texto Constituições dos Frades Capuchinhos (ORDEM DOS FRADES MENORES CAPUCHINHOS, Lisboa, 1993) - que os capuchinhos devem obediência à Igreja e devem participar ativamente das iniciativas da Igreja.

A relação entre Igreja, Jesus e Francisco recebe no discurso acima citado uma devida ordenação hierárquica, uma ordenação demonstrativa de poder nos seguintes termos: Francisco é portador de carisma que busca viver o evangelho de Jesus, obediente à Igreja, a qual se manifesta como acolhedora da proposta verdadeira de Jesus. Assim, o carisma de São Francisco é visivelmente um carisma de serviço e de amor à lgreja. O frei capuchinho se orienta por esta razão de viver.

\section{Paróquias: uma relação entre a Igreja, Carisma e promoção social}

É por meio das paróquias que muitas vezes os frades capuchinhos se instalam em uma determinada cidade e fazem valer seu carisma, trabalhando em prol da Igreja. Esta perspectiva de trabalho paroquial está ligada deste muito à vida apostólica dos capuchinhos; visto que, receber determinada paróquia do bispo, nela trabalhar e após devolvê-la ao bispo, é um processo comum na vivência dos capuchinhos. 
De modo geral, a identificação da relação Igreja Católica Romana e Ordem Capuchinha se faz conjuntamente com a relação Igreja e Carisma de São Francisco. Esta relação acaba traduzindo-se em forma de apropriação simbólica, pois, como os carismas são destinados ao beneficio da lgreja e São Francisco foi obediente à Igreja, assim também os seus seguidores o serão.

Por meio desta relação, ao assumirem trabalhos em espaços dentro da arquidiocese, os capuchinhos passam logicamente a promover prioritariamente a expansão dos domínios da Igreja, da qual são obedientes em última instância. Percebe-se, assim, que nas paróquias e capelas onde os capuchinhos realizam suas atividades, a relação de maior preponderância é a relação de servir a Igreja. Não é dar destaque à Ordem em si, mas colaborar diretamente com a manutenção e expansão da lgreja, tendo por base o carisma de São Francisco, na questão da obediência à Igreja.

No caso especifico deste trabalho, os freis capuchinhos estão originalmente estabelecidos na cidade de Curitiba nas paróquias Nossa Senhora das Mercês no bairro Mercês e Nossa Senhora da Luz no bairro CIC.

Cabe aqui informar que as paróquias estão situadas em realidades sociais totalmente contrárias. A paróquia Nossa Senhora das Mercês, hoje, esta localizada em uma região privilegiada da cidade. Como identificam os próprios freis que lá trabalham, seus fiéis são de classe média e classe média alta. Já a paróquia Nossa Senhora da Luz está localizada em uma região periférica e de vulnerabilidade social, apresentando de maneira mais evidente situações de pobreza, violência, tráfico de drogas e outros.

Na primeira paróquia, além dos capuchinhos realizarem um trabalho de caráter fortemente espiritual, há também outra relação que os frades desenvolvem com as pessoas que frequentam a respectiva paróquia. Tal relação é o trabalho de sensibilização social; trabalho de motivar os seus participantes a colaborarem com a promoção social dos que mais precisam. A orientação dos freis é para que as pessoas que participam na Igreja das Mercês sejam levadas a refletir sobre a situação do mais pobre.

Este trabalho de conscientização realizado pelos frades entre os fieis na Igreja das Mercês busca criar uma cultura de solidariedade. Esta 
solidariedade ocorre concretamente através da relação Igreja Mercês e Paróquia Nossa Senhora da Luz, quando a Igreja das Mercês repassa dez por cento de seu dizimo àquela paróquia, para que ela o utilize em trabalhos que promovam o resgate social das pessoas necessitadas.

Esta relação não fica só na colaboração financeira; existem outros meios de favorecê-la. Há o incentivo do voluntariado, buscando que pessoas doem um pouco do seu tempo em favor dos menos aquinhoados. Este voluntariado por meio de cursos, atendimentos de saúde, que profissionais liberais, incentivados pelos freis das Mercês, acabam realizando na paróquia Nossa Senhora da Luz e também nas Mercês. Assim, surge desta relação uma troca de caráter econômico, humano e simbólico.

Percebe-se por essa dinâmica das paróquias, uma desenvolvendo o habitus franciscano de modo simbólico entre os fiéis através da conscientização e a outra materializando tudo em trabalho social. Tal dinâmica de trabalho desdobra-se em um serviço à Igreja e um serviço ao social. O povo recebe duplo amparo por parte dos frades, amparo voltado ao lado espiritual do individuo e outro voltado ao lado material dele.

$\mathrm{Na}$ paróquia Nossa Senhora das Mercês há o desenvolvimento da relação Carisma e Igreja, e Carisma e Habitus.

Também na paróquia Nossa Senhora da Luz, existe o desenvolvimento da relação Carisma e Igreja; porém, ao contrário das Mercês, ali o outro aspecto de destaque não é o fortalecimento e propagação do habitus, mas, concretizar um trabalho social em primeiro plano, para depois se projetar nitidamente o habitus franciscano.

Desta forma, nas Mercês, dá-se maior ênfase ao trabalho pastoral vinculado ao projeto da Igreja; mas fundamentado na figura dos frades, como seguidores de Francisco de Assis, pobres, humildes, acolhedores espirituais.

Na paróquia Nossa Senhora da Luz, também há um trabalho pastoral, vinculado à Igreja, e fundado na figura dos frades; porém o destaque é a ação social que em vez de atingir somente os fiéis da igreja, atingem a quaisquer que precisarem e que haja condições de atender. 
Em todo este contexto, se percebe a presença de uma territorialidade capuchinha distinta em cada uma das paróquias.

Diz-se territorialidade, pois as paróquias são territórios da Igreja, divisão estabelecida pela Igreja. Porém, a partir da prática dos frades nestes territórios, eles também imprimem suas características básicas, ou melhor, as marcas do seu carisma, que acabam determinando certa territorialidade franciscana. Portanto se estabelece uma relação clara de poder, onde a apropriação do trabalho capuchinho pela Igreja, visando manter e expandir seus domínios de base acaba permitindo também que o carisma franciscano possa ser propagado e mantido em práticas ali vivenciadas; espirituais ou sociais.

Deste modo, se verifica que na paróquia Nossa Senhora das Mercês a territorialidade remete ao habitus, pois, é um local de referência simbólica da presença capuchinha e se volta prioritariamente ao aspecto espiritual.

Por outro lado, a paróquia Nossa Senhora da Luz oscila de modo diverso da Paróquia Nossa Senhora das Mercês; pois além de referendar o território da Igreja e desenvolver uma territorialidade capuchinha demonstrada a partir da presença dos freis, existe a relação com a cidade, com o poder público.

Esta relação dá-se no momento em que os capuchinhos estabelecem como prioridade o atendimento social que, neste local, desenvolvem. Ao proporcionar a assistência social, o resgate humano das pessoas, independentemente da sua religiosidade, fica claro que a ordem quer assumir espaços que são responsabilidades do Estado, ocasionando certa ruptura no território especificadamente religioso. Portanto a conciliação entre espiritual e social, delimita novas territorialidades com escolhas efetivadas pelos agentes ali estabelecidos. No caso da paróquia Nossa Senhora da Luz, há então uma territorialidade que reproduz a relação carisma e Igreja e outra que se preocupa em estabelecer relações entre carisma e cidade. 


\section{Casa Provincial, Convento e Casa de Oração: A promoção do habitus}

O viver bem e fraternalmente está na base do ideal do viver franciscano; que se materializa na constituição de uma fraternidade, a célula geradora da Ordem Franciscana. A comunidade de irmãos que Francisco instituiu se estabelece a partir de uma convivência comunitária de trocas humanas em um espaço humilde, retirado, e que se origina da porciúncula.

Os espaços internos da Ordem funcionam como locais de resgate real dos ideais franciscanos para os que dele vivem. São espaços que remetem a organização da instituição, promoção de exercícios de convivência fraterna dos freis, de momentos de oração e contemplação.

Ao serem consideradas as funções objetivas manifestadas destes locais específicos da Ordem Capuchinha pode-se notar que nos mesmos existe uma relação entre o carisma e o habitus. Ao passo que os freis vivenciam o ideal franciscano, tendo que reavivá-lo com determinadas práticas, percebe-se que no espaço do Convento e da Casa de Oração, ficam evidentes as relações bem especificas entre o Carisma e o Habitus dos freis capuchinhos.

Pois, mesmo sendo o convento um lugar de organização bem formalizada, com horários e tarefas bem definidos, não deixa de ser um espaço de formação e manutenção do habitus franciscano. A Casa de Oração de modo semelhante é também um espaço que realiza uma importante função na formação dos freis, pois é local para promover o desenvolvimento do carisma franciscano, de reavivar o habitus que está incorporado pelos frades capuchinhos. Este espaço de conviver fraternamente, orar, reabastecer-se, contemplar e reavaliar a vida em busca de uma melhor realização da vocação dos frades é certamente fundamental para a manutenção e propagação do carisma.

Pelas razões acima, estes locais podem ser considerados territórios próprios da Ordem, quando relacionados à Igreja, e sendo territorialidades de base dentro da própria Ordem Capuchinha.

Esta territorialidade base, de condição interna, dá-se indubitavelmente pelo fato de os mesmos locais servirem exclusivamente à formação dos frades, favorecendo todo o desenvolvimento do seu carisma. 
Em relação a Casa Provincial que cumpre o papel de administração central, identifica-se os ideais franciscanos, no modo como parte da mesma as orientações e a gestão relativa a Ordem, como se fosse uma guardiã das vivências da província, bem como sua orientadora. Ela acaba por manter e propagar o carisma de Francisco ao conjunto institucional da Província São Lourenço de Brindes, estabelecendo uma relação entre o Carisma Franciscano e o Habitus presente na vida dos freis que a compõem.

Este propagar e manter vivo o carisma, a partir das decisões e orientações do ministro superior ou da secretaria ou do economato, faz da sede provincial, um local, um território hierárquico da ordem. Acaba por representar uma delimitação institucional da Ordem Capuchinha e centraliza as informações necessárias a vivência da mesma.

Portanto a relação entre o carisma e a Ordem se cristaliza também na sede provincial, apesar de estar ela mais relacionada ao aspecto funcional e administrativo da ordem e não da formação espiritual dos freis.

Mais uma vez percebe-se o quanto carisma pode ser fluido e articulado em suas relações.

Para melhor visualização da
dinâmica do carisma franciscano em
Curitiba, apresentamos o
"Representação das principais relações desenvolvidas a partir do carisma de São Francisco" que busca representar de forma simbólica as relações prioritárias da Ordem; que é especificamente a identificação formal das relações que o carisma faz com a Igreja, com o Habitus e com a questão social.

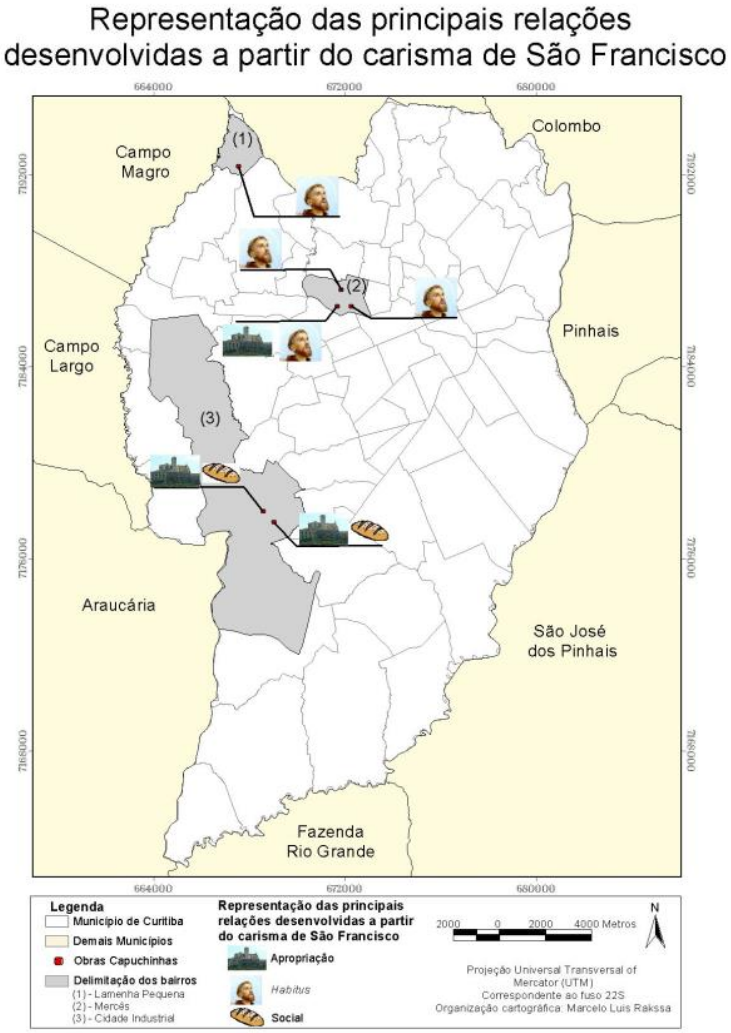




\section{CONSIDERAÇÕES FINAIS}

Orientado por questões pertinentes à ideia de que era possível traduzir carisma como poder, sendo São Francisco fundador e inspirador de uma ordem religiosa que o identifica como indivíduo carismático, esta análise desvela que a partir para uma investigação nas fontes de orientação capuchinha e dos membros da Ordem dos Frades Menores Capuchinhos, relacionando-as aos locais capuchinhos na cidade de Curitiba, identifica-se uma série de relações de poder.

Desta exploração e articulação teórica dos conceitos de carisma, habitus, e território/territorialidade, retiradas das ideias de autores como Max Weber e Leonardo Boff, com suas ideias de carisma, Pierre Bourdieu, com seu conceito de habitus, e Claude Raffestin, Gil Filho sobre o território/territorialidade, o trabalho buscou explorar cada conceito, criando uma rede de situações onde eles se relacionassem ao carisma de São Francisco diretamente.

Ao explorar a história de Francisco, sua relação com a Igreja e com a Ordem, pode-se demonstrar como o carisma poderia ser cristalizado em determinado território e gerar também certas territorialidades, quando relacionadas estas estruturas estruturadas, não deixando de perceber que 0 território se tornava por excelência o local específico de relações de poder. E o carisma de Francisco, tido como estrutura estruturante, mantendo e desenvolvendo tais relações.

Esta identificação acabou revelando a existência de territorialidades hierárquicas e de base dentro da Ordem Capuchinha, podendo traduzi-las como território ou territorialidade, quando relacionadas a outras estruturas.

Cada um dos locais estudados foi entendido a partir do território próprio da Ordem, em que os agentes diretamente atuantes seriam os freis capuchinhos e que eles seriam considerados portadores do carisma franciscano que, incorporado, se tornaria habitus, e se faria cristalizado nas relações que a ordem desenvolve.

Em cada análise a meta foi compreender a presença do carisma como força estruturante, como elemento justificador, para que as relações de poder 
manifestadas a partir da relação com cada estrutura estruturada fossem mais bem expostas; seguindo inteiramente a ideia de que o carisma de Francisco se relacionava majoritariamente a três bases: Carisma e Igreja, Carisma e Habitus e Carisma e Fator Social.

Demonstradas as relações de poder desenvolvidas e mantidas prioritariamente a partir do carisma como estrutura estruturante com as chamadas estruturas estruturadas, se constatou uma constituição de certas territorialidades e territórios específicos envolvidos a estas estruturas.

Todo este processo de relações acaba por revelar uma operacionalidade do conceito de carisma nos estudos geográficos, bem como das próprias estruturas a ele relacionadas. A potência articuladora do carisma, assim como sua capacidade fluida, faz dele um elemento facilitador na constituição de relações de poder. Portanto estudar e aprofundar estudos que 0 utilizem é adentrar mais ainda no mundo das relações de poder.

\section{REFERÊNCIAS BIBLIOGRÁFICAS}

BIBLIA. Português. Bíblia Sagrada. Tradução de Padre Antonio Pereira de Figueredo. Rio de Janeiro: Encyclopaedia Britannica, 1980. Edição Ecumênica.

BOFF, L. Igreja: Carisma e Poder: Ensaios de Eclesiologia Militante. Editora Ática, São Paulo, 1994.

BOURDIEU, P. O Poder Simbólico. 6aㅗ ed. Rio de Janeiro: Bertrand Brasil, 2003.

A Economia das Trocas Simbólicas.São Paulo: Perspectiva, 2002.

CAPUCINHOS, Constituições da Ordem dos Frades Menores. Lisboa, 1993.

Conhecendo os Freis. Org. Frei Daniel Heinzen, Frei Luiz Antônio Frigo, 2 ${ }^{a}$ Ed. Ponta Grossa, 2000.

CATÓLICA, Igreja. Catecismo da Igreja Católica. Editora Vozes; Edições Paulinas; Edições Loyola; Editora Ave-Maria, 1993.

ELIADE, M. O Sagrado e o Profano: A essência das religiões. São Paulo: Martins Fontes. 2001.

GIL FILHO, S. F. Igreja Católica Romana: Fronteiras do Discurso \& Territorialidade do Sagrado. Tese (Doutorado em História). Setor de Ciências Humanas, Letras e Artes, Universidade Federal do Paraná, Curitiba, 2002a.

Por uma geografia do Sagrado. In: MENDONÇA, F.; KOEZEL, S. (org.) Elementos de Epistemologia da Geografia Contemporânea. Curitiba: Editora UFPR, 2002b. 
. Estruturas da territorialidade católica no Brasil. Scripta Nova. Barcelona: Universidad de Barcelona, 15 de enero de 2006, vol. X, núm. 205. Disponível em: <http://www.ub.es/geocrit/sn/sn-205.htm> Acesso em 02/05/2008.

. Igreja Católica Romana em Curitiba: Estruturas da Territorialidade sob o pluralismo religioso.RA'EGA O Espaço Geográfico em Análise. Curitiba: Departamento de Geografia/UFPR, Ano 7, v. 7, 2003.

- Geografia da Religião: Reconstruções teóricas sob o Idealismo Crítico. In: KOZEL, S.; SILVA, J. C.; GIL FILHO, S. F. (org.) Da Percepção e Cognição a Representação: Reconstruções Teóricas da Geografia Cultural e Humanista. São Paulo: Terceira Margem; Curitiba: NEER, 2007.p.207-222.

KULAITIS, L. F. M. A Trajetória social da Irmã Araújo: Serviço e Contemplação. Dissertação (Mestrado em Sociologia). Setor de Ciências Humanas, Letra e Artes, Universidade Federal do Paraná, Curitiba, 2004.

MERLO, G. G. Em nome de São Francisco: história dos Frades Menores e do Franciscanismo até início do século XVI. Petrópolis, RJ: Vozes. 2005

RAFFESTIN, C. Por uma Geografia do Poder. Tradução Maria Cecília França. São Paulo: Editora Ática S.A., 1993.

RAMOS, D. F.; AMBRÓSIO, A. Max Weber e Michel Foucault: Uma Análise Sobre Poder. Revista Universo Administração, v. 1, ano 1, jun/dez 2006. p.54-64.

ROSENDAHL, Z. Território e territorialidade: Uma perspectiva geográfica para o estudo da religião. Revista Eletrônica de Jornalismo Científico. 2004.

Disponível em: http://www.comciencia.br/reportagens/2005/05/12.shtml. Acesso em 15/06/2007.

SAMMON, S. D. S. G. Tornar Jesus Cristo conhecido e amado; a Vida Apostólica Marista hoje. Circulares do Superior Geral dos Irmãos Maristas. Volume XXXI, № 3, Roma. 2006.

WEBER, M. Economia e Sociedade: fundamentos da sociologia compreensiva. Volume 1. 3aㅗ. Edição. Brasília: Editora Universidade de Brasília, 2000.

Economia e Sociedade: fundamentos da sociologia compreensiva.

Volume 2. 3a . Edição. Brasília: Editora Universidade de Brasília, 1999.

. Max Weber: sociologia. (Gabriel Cohn org.). São Paulo: Ática, 1979.

Recebido em 30/04/2012.

Aceito em 29/11/2012. 